\title{
The Role of English Language and Literature in Cultivating Students' Language Skills
}

\author{
Weixiang Liu and Peng Yang \\ Science and Technology Institute of Nanchang University,Nanchang,330029
}

Keywords: Literature; English; Language Skills; Role

\begin{abstract}
Literature is a kind of art that reflects the objective reality in the form of language and words. Literature is the carrier of the image of art, so it is different from music, sculpture, painting and other art forms. Literature can get rid of the binding of specific material materials, be free from time and space constraints, reflect a wide range of rich social life and directly characterize the complex and delicate inner world. The cultivation of language skills is inseparable from literature. Literature can stimulate the interests of language learning, provide rich and vivid materials, make learners seem to be immersive and unknowingly complete the accumulation of vocabulary, the infiltration of grammar and the formation of language sense. At the same time of getting the ability of understanding, the ability of outputting language also forms. With the improvement of literary literacy, language skill also increases from the basic understanding and expression to deep understanding and literary expression. The study of English language and literature has an important influence on improving students' skills to use language.
\end{abstract}

\section{Introduction}

Language skills are the basic competencies that the talents of today's society must possess. In modern society, the interaction between people is mostly achieved by language. For students, to enhance their language expression skills is an important means to enhance their communication ability. The good language skill is also the basis for students to establish a good interpersonal relationship in the society. At present, the social competition is very intense. After entering the society, students also must have strong language skills in order to effectively deal with all kinds of relationships in order to effectively develop in social competition. But now the language skills of students are poor. In the process of dealing with people, it is even difficult for them to put their own minds with the appropriate language. There are many reasons for this problem. English language and literature education has important role in the cultivation of students' language skills and the promotion of students' English ability. English language and literature education can effectively provide students with literature and language knowledge, to expand the students' thinking space and rich students' visions, so that students can experience the language practice activities, which can effectively improve the language skills of students. Therefore, in school education, it is necessary to pay attention to English language and literature education and to pay attention to cultivate students' language skills.

\section{The Composition of Students' Language Ability}

If you want to use language, you should first have a deep language foundation. The language foundation mainly includes two parts: morphology and syntax. Morphology is the basis for students to be able to communicate semantically and rationally, and the syntax is the basis for students to be able to communicate meaningfully. In short, morphology is the use of vocabulary and syntax is a reasonable way to form a sentence.

For example, English became less like German because those who ruled England first spoken first Danish and later French. Really read this sentence, it is found that this sentence has a very clever arrangement both in morphology and syntax. To the morphology point of view, "became" shall be followed with verb prototype, so the latter word "like" is in the form of verb prototype. 
In addition, this sentence is generally in a past tense, in which "became", "ruled", "spoken" and other words are used in the form of participle. At the same time, the use of the word "rule" well expressed that the British was in "colonial" state. From the syntactic point of view, the whole sentence consists of two clauses - a clause is led by "because", and the latter one is another clause. In this sentence, the word form of each verb represents the time of each event is in the past. The use of several verbs can describe the occurrence of the event well; the two clauses are used interchangeably under the conjunction "because", which both has the beauty of English sentences, and expresses the most meaning with the least words.

The solid grasp of basic knowledge is the prerequisite for practical application and a prerequisite for enhancing the beauty of language. The sentence which is in line with English expression can help students to communicate properly. For another example, in the novel The Catcher in the Rye, Apart from tears, only time could wear everything away. While feeling is being processed by time, conflicts would be reconciled as time goes by. Author brief introduction: Chen Ruojing, graduate student, lecturer. Research direction: Applied linguistics, teaching method.

\section{An Analysis of the Composition of Students' Language Skills}

The language ability of students forms on the basis of a certain language-related knowledge of students after learning. To express their inner feelings and to pass the necessary communication information through language all need related language skills. In a word, if there are no corresponding language skills, the language will lose the corresponding communication functions and the corresponding knowledge student learn will lose the foundation of existence. A person's language skill is generally composed of the following parts: the basic knowledge of language, language communication skills, language rhetoric, life taboo in language use of and other components.

\section{The basic Knowledge of Language}

The basic knowledge of language is the basis of language use. If there is no necessary basic language knowledge, students cannot form a certain language skills. Because the language communication which does not conform to language norms cannot be understood by both sides of language communication, and the language communication which cannot be understood by both sides of the language communication will be a useless topic. The basic knowledge of language generally consists of two basic knowledge, that is, English morphology and English syntax.

Language Communication Skills in Different Contexts. With the basic knowledge of language, students have a certain ability to communicate. However, in the process of language communication in daily life, students do not only need to skillfully apply the basic knowledge of these languages, but also need to master certain communication skills in the specific use of language communication process. Language communication is a complex process. Different people will have different ways of expression for the same meaning, while in different contexts, the same person will also have different ways of expression. A person will euphemistically express the ideas or straightforwardly express the sentiment. All of this must be associated with a certain language environment. In other words, the context of language will have a certain impact on communication, and the clever treatment of language communicators on the impact of the context is the specific expression of language skills.

Language Rhetoric. Students' language communication can be classified according to their characteristics in the process of communication, students can be divided into oral English communication and written language communication. However, both in oral communication and written language, students need to master a certain rhetoric art. In Chinese, the original meaning of rhetoric is to use a variety of methods to modify the specific words of the communicator. When taking English as the medium of expression of emotion, students also need to use a variety of methods in the specific process of communication to make their own language both can accurately express their own ideas and can be correctly understood by the other side of the communication 


\section{The Role of English Language and Literature in Cultivating Students' English Language}

The Introduction of Literature can Stimulate English Learning Interests. The rich and varied vocabulary, expression and wonderful chapters in literary works present the exquisite and charm for learners, which is more attractive than the illustrative or expositive language materials and can stimulate the intrinsic motivation of learning. At the same time, literary works reflect the vast world and complex people, can mobilize learners to participate and think, so that their learning states will be changed from passive to active. Through the study and accumulation of literary works and the improvement of literary literacy, personal language ability will also be strengthened.

Literary Works can Provide Rich and Vivid Language Materials. Literary works contain inexhaustible language materials. On the one hand, it uses language to create artistic image, be free from time and space constraints and can always reflect the endless social life and the world's face; on the other hand, it can directly depict the complex and subtle hearts of the characters truly. The literary work library is the language library where there are amazing language materials which can be drawn.

Therefore, on the basis of the original Chinese literary literacy, to contact, understand and absorb a large number of English language materials is helpful to consolidate and deepen the basic knowledge of language and to learn the vivid language and authentic expression method. The rich and emotional literature provides the specific context of the vocabulary and helps the learner understand.

Literature Learning helps to Create Context and Shorten the Gap between time and space. Since English is not our mother tongue, the biggest obstacle in learning is that there is no beneficial language environment. In addition to communicating with native speakers of English, the simplest and most effective way is to read foreign literature. Literature itself is the combination of language and culture. Literature is the most vivid and the easiest material to understand a nation's temperament, social relations, cultural characteristics, customs and psychological states. When reading a literary work, the learner seems to enter the world which is created by the author based on real life and to feel the use of different languages in different situations. Learning is not only the words or grammar. Immersing in the target language, learners can better learn and master English.

\section{Conclusion}

English language and literature education shall enhance the language skills of students. First of all, guide students to carry out a large number of reading practice to improve students' sense of language. In the process of English language and literature teaching, each teacher emphasizes the importance of language sense, but language training requires a lot of reading practice, which means students need to read and accumulate. Therefore, to develop the good language skills, teachers need to be able to guide students to read a lot, from quantitative to qualitative change, so as to enhance students' language skills. Secondly, to clear the learning objectives of English literature so as to guide students to consciously learn to improve language skills.

\section{References}

[1] Liang L. Depicting Chinese parenting during the early years : a systematic review of the English language literature[J]. 2014.

[2] Matsumoto S. Literature and Language Education : An Analysis of Questionnaire Responses of First-Year English Majors at Bukkyo University (4)[J]. Journal of the Faculty of Letters, 2015, 99:57-72.

[3] Upadhyay H. English Language 。 Literature for the Students of English Literature[J]. 2016.

[4] Kamtchueng L M M. Non-standard Idioms in Cameroon English Literature and Their Impact on English Language Learning and Intelligibility[J]. Theory 。 Practice in Language Studies, 2014, 4(8). 
[5] Gilakjani, Abbas Pourhosein|Sabouri, Narjes Banou. Learners' Listening Comprehension Difficulties in English Language Learning: A Literature Review.[J]. English Language Teaching, 2016, 9(6):123.

[6] Owolabi D. The Domestication of the English Language for Literary Purpose in Nigeria: Creating a National Identity[J]. 2017:488-492.

[7] Zhang X. A critical review of literature on English language teaching textbook evaluation: What systemic functional linguistics can offer[J]. Journal of Language 。 Cultural Education, 2017, 5.

[8] Mohammed A, O'Neill G, Karcher A M, et al. Actinobacillus hominisosteomyelitis: First reported case in the English language medical literature:[J]. Jmm Case Reports, 2016, 3(3).

[9] Scheidler J M. Mexican American English language learners in Arizona: a literature review[J]. International Journal of Teaching 。 Case Studies, 2014, 5(3/4):314.

[10]Zaid M A. Effectiveness of Using Literature for Teaching English Language Writing Skills[J]. 2015.

[11] Zhuang P, Cheng L. About English-language Scholarship on Humor in Ancient Chinese Literature[J]. CLCWeb - Comparative Literature and Culture, 2015, 17(1).

[12] Abdelaziz B. Techniques for Selecting and Evaluating English Language Literary Texts[J]. 2014(19):7-14. 